\title{
Heart Team 2.0: Keep your friends close... and your enemy closer!
}

\author{
From the ${ }^{\mathrm{a} D e p a r t m e n t ~ o f ~ C a r d i o t h o r a c i c ~ S u r g e r y, ~ W e i l l ~ C o r n e l l ~ M e d i c i n e, ~ N e w ~ Y o r k, ~ N Y ; ~ a n d ~ t h e ~}{ }^{\mathrm{b}}$ Department of \\ Cardiovascular Sciences, Catholic University, Rome, Italy. \\ Disclosures: Authors have nothing to disclose with regard to commercial support. \\ Received for publication Oct 10, 2017; accepted for publication Oct 13, 2017; available ahead of print Nov 29, \\ 2017. \\ Address for reprints: Mario Gaudino, MD, FEBCTS, Department of Cardiothoracic Surgery, Weill Cornell Med- \\ icine, 525 E 68th St, New York, NY 10065 (E-mail: mfg9004@med.cornell.edu). \\ J Thorac Cardiovasc Surg 2018;155:874 \\ $0022-5223 / \$ 36.00$ \\ Copyright $\odot 2017$ by The American Association for Thoracic Surgery \\ https://doi.org/10.1016/j.jtcvs.2017.10.050
}

Mario Gaudino, MD, ${ }^{\mathrm{a}}$ Filippo Crea, MD, ${ }^{\mathrm{b}}$ Massimo Massetti, MD, ${ }^{\mathrm{b}}$ and Leonard N. Girardi, MD

In this issue of the Journal, Ram and colleagues ${ }^{1}$ present an intriguing study that is based on the mandatory Israeli Multivessel Coronary Artery Disease Registry. Ram and colleagues ${ }^{1}$ have used this large and extremely complete registry to evaluate the impact of the Heart Team discussion on the decision-making process and the outcomes of patients with multivessel coronary disease. Not surprisingly, they found that in the absence of a Heart Team, significantly more patients are inappropriately treated with percutaneous interventions. Centers with a Heart Team in place adopted more appropriate criteria to refer patients for coronary artery bypass grafting surgery and had significantly better midterm survival with coronary artery bypass grafting than did centers without a Heart Team.

Team discussion has been part of the decision-making process for many years in oncology and in organ transplantation. In the cardiovascular field, the Heart Team evaluation for coronary revascularization was introduced in clinical practice after the SYNTAX (Synergy between PCI with Taxus and Cardiac Surgery) trial. In recent years, the Heart Team approach has been extended to valvular pathologies, congestive heart failure, and congenital diseases.

In the field of coronary revascularization, even in absence of randomized trial evidence, it is generally accepted that a multidisciplinary discussion including at least 1 cardiac surgeon, 1 invasive cardiologist, and 1 clinical cardiologist is the best way to ensure patient-oriented (as opposed to physician-oriented) treatment. Despite the recommendations of the US and European guidelines however, the Heart Team approach has been embraced with variable enthusiasm and with considerable geographic variation around the world. ${ }^{2}$

Even though cultural factors and communication problems have certainly played a role, logistic difficulties in having all Heart Team members together at the same time are often used to justify this slow adoption rate (as in the article by Ram and colleagues ${ }^{1}$ ). In the era of Internet and 24-7 connection, logistic reasons should no longer be part of such as those described by Ram and colleagues. participate in the multidisciplinary approach.

\section{References} cardiac surgery. J Thorac Cardiovasc Surg. 2018;155:865-73.e3. 2017;69:681-3.

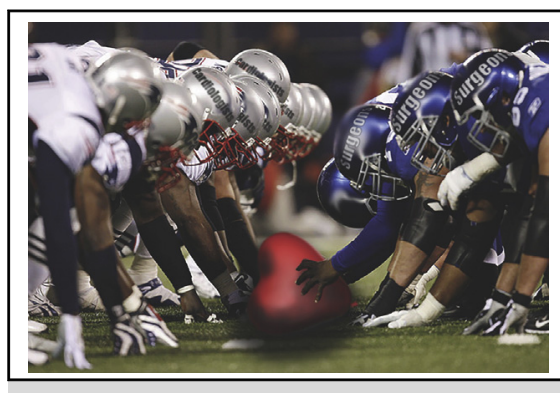

Heart Team 2.0: Cardiologists versus Surgeons

Central Message

In the era of nonstop connection, logistic reasons cannot justify lack of participation in the Heart Team discussion. Cardiologists and cardiac surgeons must use technology to stay connected.

See Article page 865

the equation. A smartphone or a tablet is all that is needed to participate in the multidisciplinary discussion from any location. Protection of personal data and health information is easily achievable with current technology. Remote Heart Team meeting (the Heart Team 2.0) has been in place in our institutions for a number of years. It allows urgent or emergency consultation at every hour of the day and easy extension of the Heart Team process to remote primary hospitals,

The future of the Heart Team will include the participation not only of cardiologists and cardiac surgeons but also of radiologists, vascular surgeons, rehabilitation specialists, and a wide spectrum of multidisciplinary consultants, with the aim of achieving a truly personalized treatment for every patient. For the moment, however, implementation and participation in multidisciplinary discussions, even remotely and with every possible technologic aid, should be viewed as a primary responsibility by both cardiologists and cardiac surgeons. As we are appropriately reminded by Ram and colleagues, ${ }^{1}$ our patients are those who will ultimately benefit the most from our efforts to

1. Ram E, Goldenberg I, Kassif Y, Segev A, Lavee J, Shlomo N, et al. Comparison of patients with multivessel disease treated at centers with and without on-site

2. Yadava OP. 'Heart team' concept—a reality or a 'platonic illusion.' Indian Heart J. 